\title{
The Recto-Vesical Ligament: Myth or Reality?
}

\author{
Raja Briki, Ons Cherif*, Mouna Derouich, Salma Chachia, Sassi Boughizane, Hedi Khairi \\ Department of Gynecology and Obstetrics, Farhat Hached University Hospital, Sousse, Tunisia \\ Email: *onscherifb@gmail.com
}

How to cite this paper: Briki, R., Cherif, O., Derouich, M., Chachia, S., Boughizane, S. and Khairi, H. (2018) The Recto-Vesical Ligament: Myth or Reality? Open Access Library Journal, 5: e4911.

https://doi.org/10.4236/oalib.1104911

Received: September 17, 2018

Accepted: November 19, 2018

Published: November 22, 2018

Copyright () 2018 by authors and Open Access Library Inc.

This work is licensed under the Creative

Commons Attribution International

License (CC BY 4.0).

http://creativecommons.org/licenses/by/4.0/

\begin{abstract}
The recto-vesical ligament is an abnormal peritoneal band that can be associated with uterine malformations by default fusion of Müller's ducts. It is a very rare entity. We report a case of laparoscopic surgery conducted on a 28-year-old patient in order to explore primary subfertility. We discover that the patient had two permeable vaginas, two distinct cervices and two completely separate hemiuterus with two horns between which a wide peritoneal band attached to the bladder and back to the sigmoid: the ligament recto-vesical.
\end{abstract}

\section{Subject Areas}

Gynecology \& Obstetrics, Internal Medicine, Women's Health

\section{Keywords}

Recto-Vesical Ligament, Bicornuate Uterus, Müller's Duct, Didelphys Uterus

\section{Case Report}

A 28-year-old had consulted for wish of pregnancy. It was a history of primary subfertility whose etiological record had concluded tubal origin. A laparoscopy of tubo-peritoneal evaluation was performed, and allowed the discovery of a double uterus: bicornuate bicollis uterus with permeable vagina. The patient had two permeable vaginas, two distinct cervices and two completely separate hemiuterus with two horns between which a wide peritoneal band attached to the bladder and back to the sigmoid as shown in Figure 1: the ligament recto-vesical (Figure 2).

Furthermore, the exploration of the pelvic cavity showed the presence of peritoneal endometriosis superficial stains as shown in Figure 3.

\section{Discussion}

The recto-vesical ligament is an abnormal peritoneal band that can be associated 


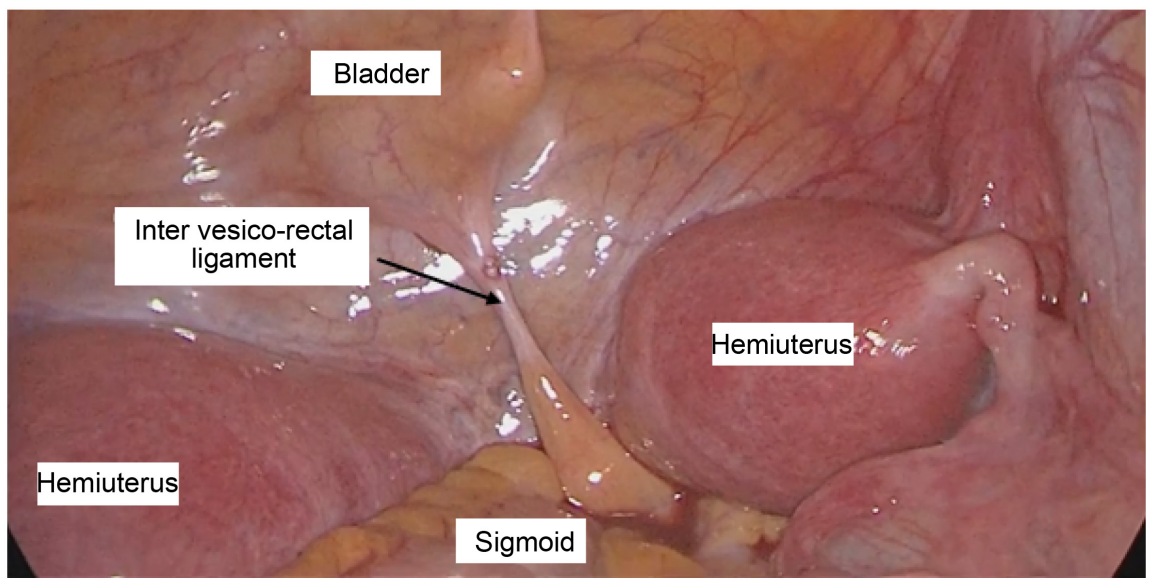

Figure 1. Laparoscopic view of the pelvis.

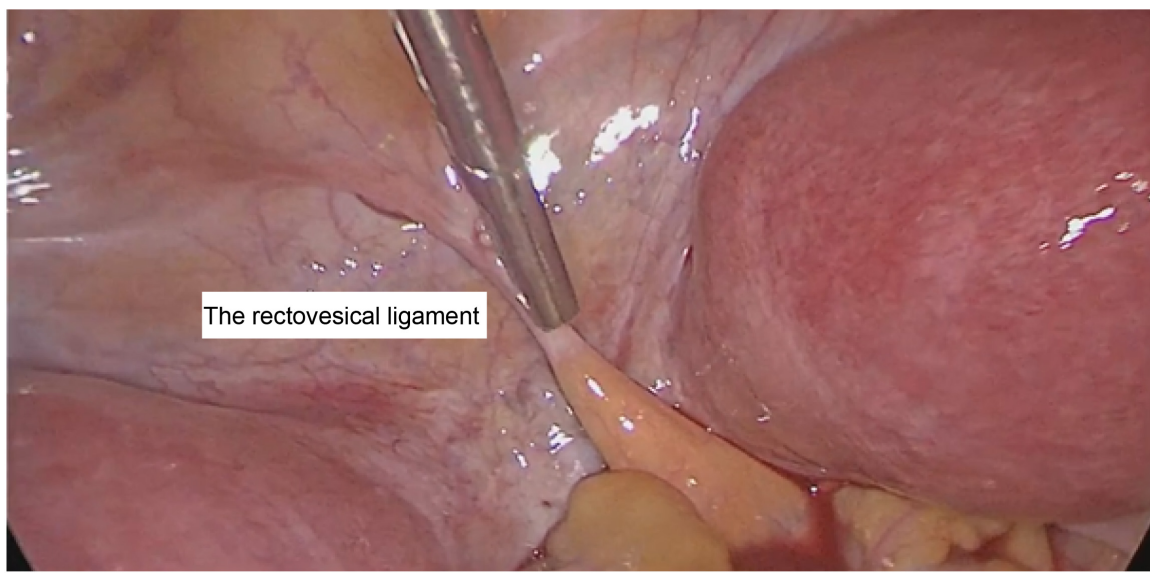

Figure 2. The recto-vesical ligament.
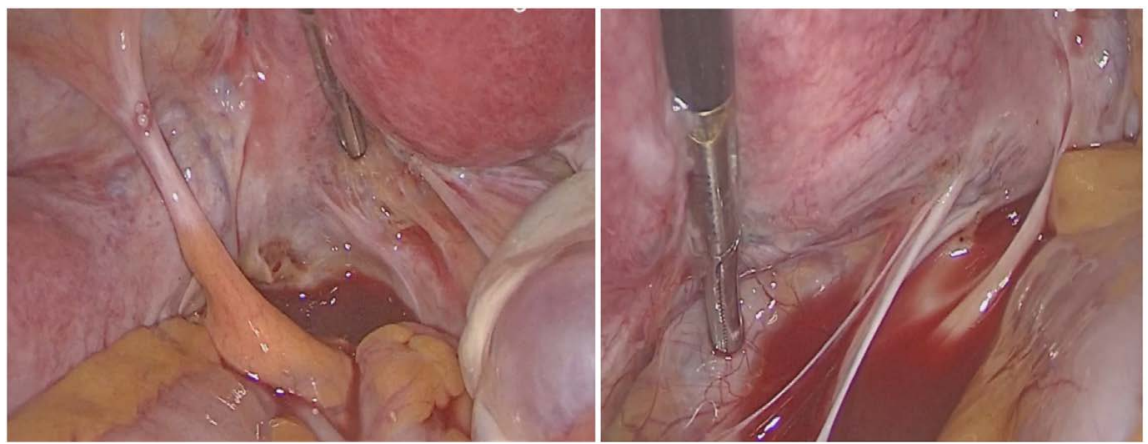

Figure 3. Signs of superficial peritoneal endometriosis.

with uterine malformations by default fusion of Müller's ducts. It is a fold of connective tissue extending from the rectum to the bladder, crossing the junction between the two horns of the uterus [1]. It is a very rare entity [2] [3] that associates with the didelphys uterus and that extends between the bladder forward and the anterior face of the recto-sigmoid back, thus separating the two hemi-matrices of the bicornuate uterus [2]. This anatomical variant is associated with the bicornuate bicollis uterus class III according to the American Fertility 
Society/American Society for Reproductive Medicine (AFS/ASRM) classification [4]. In this case, the uterus may be a bicornuate bicollis permeable or with obstructed hemivagina [5]. Concomitant renal abnormalities are possible [3] [5].

\section{Conclusion}

The recto-vesical ligament is not only a consequence of the failure of the Müller's duct fusion, but its relation to the uterine malformation with or without vaginal and/or renal abnormality indicates a certain part of this structure in the early development of the urogenital system [3].

\section{Conflicts of Interest}

We declare that we have no conflict of interest.

\section{References}

[1] Tow, S.H. (1960) The Double Uterus. A Review of Twenty-One Cases. Singapore Medical Journal, 1, 167-171.

[2] Jayi, S. and Abdelilah Melhouf, M. (2013) Inter-Vesico-Rectal Ligament Separating the Half-Matrices of a Unicervical Uterus Bicornis-About A Rare Case. Pan African Medical Journal, 15, 27. https://doi.org/10.11604/pamj.2013.15.27.2773

[3] Heinonen, P.K. (2013) Rectovesical Ligament and Fusion Defect of the Uterus with or without Obstructed Hemivagina and Ipsilateral Renal Agenesis. European Journal of obstetrics, Gynecology, and Reproductive Biology, 168, 83-86. https://doi.org/10.1016/j.ejogrb.2012.12.034

[4] The American Fertility Society (1988) The American Fertility Society Classifications of Adnexal Adhesions, Distal Tubal Occlusions, Tubal Occlusion Secondary to Tubal Ligation, Tubal Pregnancies, Mullerian Anomalies and Intrauterine Adhesions. Fertility and Sterility, 49, 944-955. https://doi.org/10.1016/S0015-0282(16)59942-7

[5] Fedele, L., Motta, F., Frontino, G., Restelli, E. and Bianchi, S. (2013) Double Uterus with Obstructed Hemivagina and Ipsilateral Renal Agenesis: Pelvic Anatomic Variants in 87 Cases. Human Reproduction, 28, 1580-1583.

https://doi.org/10.1093/humrep/det081 